\title{
Effects of Enterally Administering Granulocyte Colony-Stimulating Factor to Suckling Mice
}

\author{
JASON A. GERSTING, ROBERT D. CHRISTENSEN, AND DARLENE A. CALHOUN \\ Department of Pediatrics [J.A.G.], University of Florida, Division of Neonatology, Gainesville, FL 32610, \\ U.S.A.; and University of South Florida/All Children's Hospital [R.D.C., D.A.C.], Children's Research \\ Institute, St. Petersburg, FL 33701, U.S.A.
}

\begin{abstract}
ABST
Gastrointestinal (GI) tract development is influenced by mul-
tiple growth factors, some of which are delivered directly to the
GI lumen, as they are swallowed constituents of amniotic fluid,
colostrum, and milk. Granulocyte colony-stimulating factor (G-
CSF), traditionally known as a granulocytopoietic growth factor,
is an example of one such factor. However, it is not clear whether
the large amounts of G-CSF that are normally swallowed by the
fetus and neonate have systemic effects on circulating neutrophils
or local effects in the developing intestine. To assess this, we
administered either active or heat-denatured (control) recombi-
nant human G-CSF to 5- to 7-d-old C57BL/6 $\times 129$ SvJ mice.
Pups received either a low dose (3 ng) that was calculated to
approximate the amount of G-CSF swallowed in utero from
amniotic fluid or an isovolemic high dose 100 times larger (300
ng). Oral dosing was performed daily for either 3 or 7 d, after
which pups were killed and measurements were made on the
blood and the GI tract. Absolute blood neutrophil counts and
immature to total neutrophil ratios did not differ from controls in
any of the test groups. However, intestinal villus area, perimeter,
length, crypt depth, and proliferating cell nuclear antigen index
\end{abstract}
The development of the gastrointestinal (GI) tract is a complex process that involves diverse cell types and requires a balance among cellular proliferation, differentiation, and senescence. Growth factors are involved in this regulation $(1,2)$, and among those factors studied are epidermal growth factor (EGF), insulin-like growth factor (IGF), erythropoietin (Epo), and transforming growth factor (3-14).

Several studies in our laboratory have suggested that granulocyte colony-stimulating factor (G-CSF), generally known as a granulocytopoietic growth factor $(15,16)$, should be included on this list as a GI trophic factor during fetal and neonatal

Received June 20, 2003; accepted November 20, 2003.

Correspondence: Darlene A. Calhoun, DO, University of South Florida/All Children's Hospital, Children's Research Institute, 140 Seventh Avenue South, CRI Room 2006, St. Petersburg, FL 33701, U.S.A.; e-mail: dcalhoun@hsc.usf.edu

Supported by grants HD-01180 (D.A.C.), HD-42326 (D.A.C.), and HL-61798 (R.D.C.) from the National Institutes of Health.

DOI: 10.1203/01.PDR.0000117846.51197.7C

increased significantly among those that were treated with active G-CSF. Thus, in suckling mice, enterally administered G-CSF had no effect on the concentration of circulating neutrophils but had trophic effects on the intestine. We speculate that the G-CSF present in amniotic fluid, colostrum, and milk acts as a topical intestinal growth factor and has little or no granulocytopoietic action. (Pediatr Res 55: 802-806, 2004)

$\quad$ Abbreviations
ANC, absolute neutrophil count
EGF, epidermal growth factor
Epo, erythropoietin
G-CSF, granulocyte colony-stimulating factor
G-CSF-R, granulocyte colony-stimulating factor receptor
GI, gastrointestinal
I:T, immature to total neutrophil ratio
rhEpo, recombinant human erythropoietin
rhG-CSF, recombinant human granulocyte-colony stimulating
factor
PCNA, proliferating cell nuclear antigen

development. G-CSF is present in significant quantities in amniotic fluid $(1612 \pm 2100 \mathrm{pg} / \mathrm{mL}$, term; $1708 \pm 1763$ $\mathrm{pg} / \mathrm{mL}$, preterm), colostrum (156 \pm 12 , term; $80 \pm 41 \mathrm{pg} / \mathrm{mL}$, preterm), and milk ( $37 \pm 21 \mathrm{pg} / \mathrm{mL}$, term; $32 \pm 18 \mathrm{pg} / \mathrm{mL}$, preterm), each of which is ingested by the fetus and the neonate (17-21). Moreover, the G-CSF in these fluids is stable during simulated digestions, suggesting that intact G-CSF reaches the GI tract in utero and postnatally $(19,20)$. We have demonstrated that the G-CSF receptor (G-CSF-R) is widely expressed in the developing fetal GI tract, where it is localized to the apical surface of enterocytes and the crypts of the intestinal villi $(18,22)$.

The exact function of the G-CSF swallowed by the fetus and neonate is not known. Potentially, it could be absorbed into the circulation and function as a hematopoietic growth factor, and/or it could have local actions in the developing GI tract. As a step toward understanding the function of the G-CSF swallowed by the fetus and neonate, we fed suckling mice either recombinant human CSF (rhG-CSF) or heat-denatured rhG- 
CSF (as a control) for either 3 or $7 \mathrm{~d}$ and thereafter measured blood neutrophils and intestinal morphometrics.

\section{METHODS}

Animals and rhG-CSF administration. C57BL/ $6 \times 129 \mathrm{SvJ}$ mice were housed in a specific pathogen-free environment. The protocols were approved by the University of Florida and the University of South Florida Institutional Animal Care and Use Committees. Two doses of rhG-CSF were tested: 3 and $300 \mathrm{ng}$. The lower dose was taken as an approximation of a "physiologic" dose, derived from the concentration of G-CSF in human amniotic fluid (17). The higher dose was a "pharmacologic" dose, arbitrarily taken as 100 times the "physiologic" dose.

The rhG-CSF (Neupogen; Amgen, Thousand Oaks, CA, U.S.A.; stock of $300 \mu \mathrm{g} / \mathrm{mL}$ ) used in these experiments was diluted with PBS ( $\mathrm{pH}$ 7.2) to deliver each dose in a total volume of $100 \mu \mathrm{L}$. Denatured rhG-CSF was produced, for use as a control, by incubating rhG-CSF for $1 \mathrm{~h}$ at $60^{\circ} \mathrm{C}$ (D.A.C. and Amgen, unpublished observations that the heat treatment of rhG-CSF under these conditions leads to no measurable G-CSF activity).

Pups, between 5 and $7 \mathrm{~d}$ of age at the start of the study, received a once-daily oral administration of $100 \mu \mathrm{L}$ of either heat-treated or untreated rhG-CSF, via an animal-feeding blunt needle (Popper and Sons, Inc., New Hyde Park, NY, U.S.A.). This was done for either 3 or 7 consecutive days. The pups were divided into six groups: group 1 received $3 \mathrm{ng}$ of denatured rhG-CSF for $3 \mathrm{~d}$, group 2 received $3 \mathrm{ng}$ of active rhG-CSF for $3 \mathrm{~d}$, groups 3 and 4 were fed $3 \mathrm{ng}$ of either denatured or active rhG-CSF for $7 \mathrm{~d}$, and groups 5 and 6 were fed $300 \mathrm{ng}$ of either denatured or active rhG-CSF for $7 \mathrm{~d}$. After each feeding, pups were returned to the cage with their mother and allowed to suckle ad libitum until the completion of the experiment. Sample sizes included a minimum of five animals in each group.

Sample collection and measurements. Twenty-four hours after the final study feeding, the pups were killed after inhalation anesthesia (methoxyflurane; Schering-Plough Animal Division, Union, NJ, U.S.A.). Whole blood from a severed carotid artery was collected directly into heparinized Natelson Blood Collecting Tubes (Fisher Scientific, Pittsburgh, PA, U.S.A.) and used for determination of a complete blood count on an automated hematology cell counter (System 9000; Baker Instruments, Allentown, PA, U.S.A.). Pulled blood films were prepared on coverslips for Wright staining to evaluate differential counts, performed under $100 \times$ oil immersion. The absolute blood neutrophil concentration (ANC) and blood immature to total (I:T) neutrophil ratio were determined. ANCs were calculated by multiplication of the total white blood cell count by the percentage of neutrophils in the 100-cell differential count (expressed as the number of cells $/ \mu \mathrm{L}$ ). The I:T ratio was determined by adding the immature myeloid series cells (band neutrophils, metamyelocytes, and myelocytes) and dividing by the total number of neutrophils (segmented and nonsegmented) (23).
The intestine was removed en bloc, and sections of duodenum were washed with saline and placed in Bouin's fixative for $4 \mathrm{~h}$, then transferred to $70 \%$ ethanol. Specimens were paraffin embedded and cut at 4- to 6- $\mu \mathrm{m}$ thickness. Slide-mounted sections were deparaffinized in xylene, rehydrated through a descending ethanol series, and processed using an automated enzyme-labeled biotin-streptavidin technique (Ventana NexES; Ventana Medical Systems, Tucson, AZ, U.S.A.) with diaminobenzidine tetrahydrochloride as the chromagen. Duodenal sections from each multiday treatment were stained with an anti-mouse proliferating cell nuclear antigen (PCNA) antibody $(20 \mu \mathrm{g} / \mathrm{mL}$; Santa Cruz Biotechnology), counterstained with hematoxylin and bluing, and dehydrated, and coverslips were applied. Morphometric analysis consisting of villus area, perimeter, length, villi $/ 500 \mu \mathrm{m}$, crypt depth, and PCNA staining index [(no. of PCNA-positive cells/no. of crypt cells) $\times$ 100] was performed using a standard light microscope and a computer Analysis Imaging Station (Imaging Research Inc., St. Catharines, Ontario, Canada) (24). The individual who performed the morphometric analyses and PCNA index determinations was blinded to the group assignment at the time of analysis.

Statistical analysis. Statistical analysis was performed on the morphometric parameters using SPSS for Windows 9.0 (Chicago, IL, U.S.A.). Using the six subgroups for classification of the animals [variables of duration of feeding, type of G-CSF received (heat treated versus rhG-CSF), and dose of G-CSF received], means of the groups were compared using a one-way ANOVA. Data presented in tables and graphically are mean values \pm SEM. An $\alpha \leq 0.05$ was used as a measure of significance.

\section{RESULTS}

Pup weights did not differ significantly between the animals assigned to each of the treatment groups. Feeding the pups rhG-CSF, at either the low or the high dose, for either 3 or $7 \mathrm{~d}$ did not produce any recognized elevation in ANC or I:T ratio (Table 1). Similarly, rhG-CSF feeding did not produce any recognized change in any of the blood parameters examined, including platelet count, $\mathrm{Hb}$ concentration, or hematocrit.

Feeding rhG-CSF (3 ng) for $3 \mathrm{~d}$ (Table 1, comparing groups 1 and 2) resulted in a larger villus area, longer villus perimeter, longer villus length, increased crypt depth, and increased mitotic activity as estimated by PCNA index (Fig. 1), but no differences were observed in number of villi along $500 \mu \mathrm{m}$ of intestinal length. When rhG-CSF (3 ng) was fed for $7 \mathrm{~d}$ (comparing groups 3 and 4), the intestinal morphometric measurements did not differ between those that were fed heatinactivated rhG-CSF and active rhG-CSF. Feeding the higher dose of rhG-CSF (300 ng) for $7 \mathrm{~d}$ (comparing groups 4 and 6) resulted in a larger villus area, longer villus perimeter, and longer villus length.

\section{DISCUSSION}

This study was designed to examine the effects of rhG-CSF administered enterally to suckling mice. We observed that neither a short-term (3 d) nor a longer-term (7 d) administration 
Table 1. Blood counts and morphometrics of experimental groups

\begin{tabular}{|c|c|c|c|c|c|c|c|c|c|c|c|c|}
\hline & \multicolumn{2}{|c|}{$\begin{array}{c}\text { Group } 13 \text {-day } \\
\text { Heat-treated } 3 \\
\text { ng }\end{array}$} & \multicolumn{2}{|c|}{$\begin{array}{l}\text { Group } 2 \text { 3-day } \\
\text { rhG-CSF } 3 \text { ng }\end{array}$} & \multicolumn{2}{|c|}{$\begin{array}{c}\text { Group } 3 \text { 7-day } \\
\text { Heat-treated } 3 \\
\text { ng }\end{array}$} & \multicolumn{2}{|c|}{$\begin{array}{l}\text { Group } 4 \text { 7-day } \\
\text { rhG-CSF } 3 \text { ng }\end{array}$} & \multicolumn{2}{|c|}{$\begin{array}{l}\text { Group } 5 \text { 7-day } \\
\text { Heat-treated } \\
300 \mathrm{ng}\end{array}$} & \multicolumn{2}{|c|}{$\begin{array}{c}\text { Group } 6 \text { 7-day } \\
\text { rhG-CSF } 300 \text { ng }\end{array}$} \\
\hline & Mean & SEM & Mean & SEM & Mean & SEM & Mean & SEM & Mean & SEM & Mean & SEM \\
\hline \multicolumn{13}{|l|}{ Blood count } \\
\hline $\mathrm{ANC} / \mu \mathrm{L}$ & 5554 & 861 & 5937 & 1825 & 2777 & 1642 & 1683 & 305 & 3534 & 537 & 1845 & 252 \\
\hline I:T Ratio & .265 & 0.03 & .261 & 0.03 & .263 & 0.04 & .201 & 0.03 & .323 & 0.05 & .432 & 0.05 \\
\hline Perimeter $(\mu \mathrm{m})$ & 527 & 12.50 & $605^{*}$ & 13.79 & 600 & 17.74 & 574 & 14.79 & 550 & 13.22 & $706 * * *$ & 12.37 \\
\hline Length $(\mu \mathrm{m})$ & 228 & 5.60 & $267 *$ & 6.33 & 262 & 8.49 & 254 & 6.97 & 256 & 6.46 & $321 * * *$ & 5.49 \\
\hline No. of villi in $500 \mu \mathrm{m}$ & 9.4 & 0.39 & 10.1 & 0.58 & 8.9 & 0.40 & 9.3 & 0.47 & 8.7 & 0.76 & 8.9 & 0.39 \\
\hline Crypt depth $(\mu \mathrm{m})$ & 45.0 & 1.35 & $49.7 *$ & 1.28 & 49.7 & 0.93 & 52.0 & 1.33 & 51.0 & 0.97 & 50.4 & 0.68 \\
\hline PCNA index $(\%)$ & 64.7 & 2.99 & $73.9 *$ & 1.54 & 74.0 & 1.34 & 70.4 & 1.74 & 73.9 & 0.82 & $74.9 *, * *$ & 0.94 \\
\hline
\end{tabular}

Mean and standard error of the mean (SEM) are given for each of the six experimental groups. Data are given for blood counts (Part A) and villus morphometric measurements (Part B).

$* p<0.05$ vs. heat-treated group.

** $p<0.05$ Group 6 vs. Group 4.
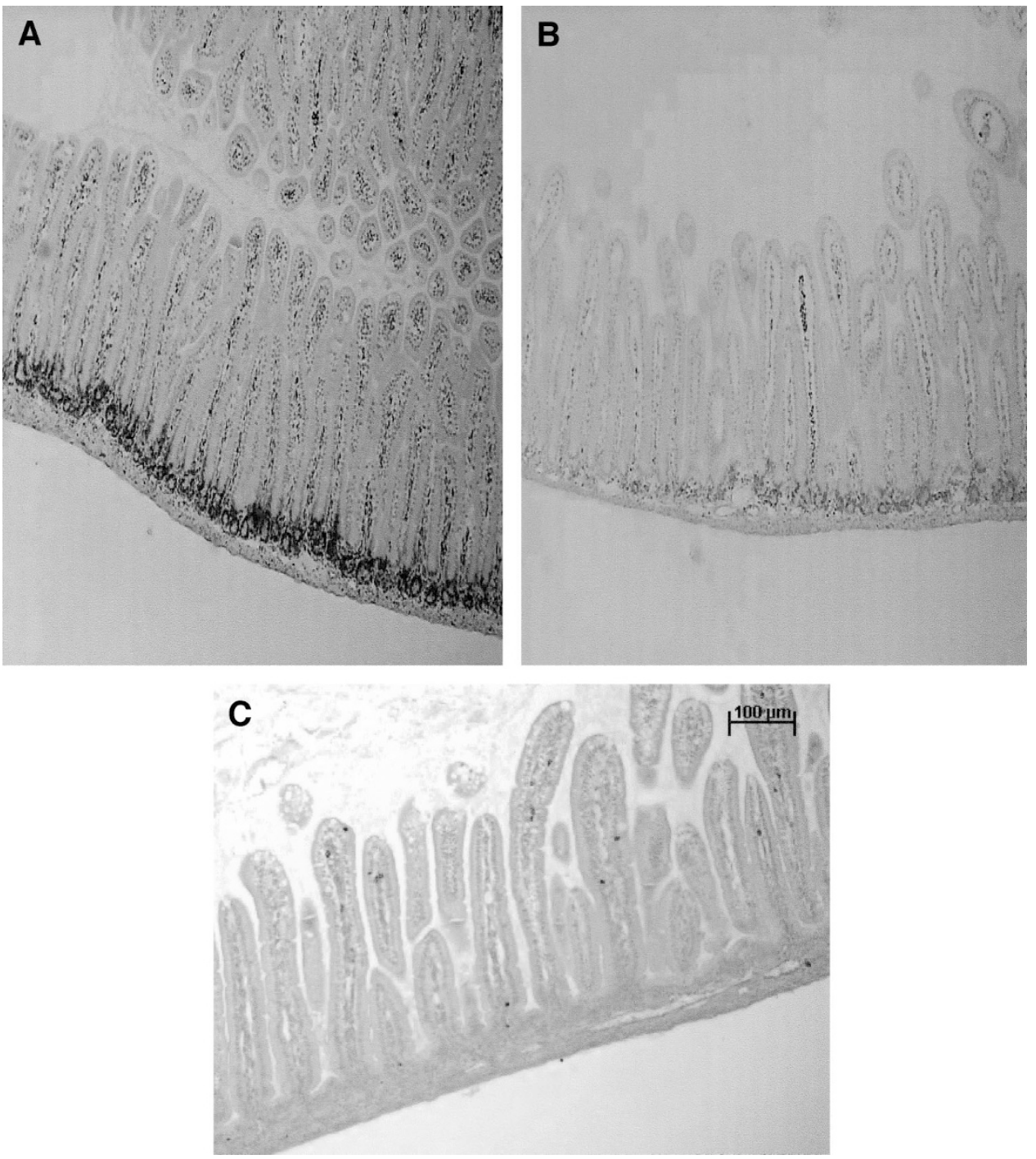

Figure 1. PCNA staining of murine intestine. Representative intestinal sections stained with an anti-PCNA antibody (brown coloration) from mice that received daily enteral rhG-CSF at $3 \mathrm{ng}$ for $3 \mathrm{~d}$ (group 1;A) and heat-treated rhG-CSF at $3 \mathrm{ng}$ for $3 \mathrm{~d}$ (group 2; B). (C) Negative control. Magnification: $\times 200$.

of either a physiologic or a pharmacologic dose of rhG-CSF produced any recognized change in circulating neutrophil concentration but did have trophic effects on the bowel. In addition, the administration of a pharmacologic dose did not result in any observed adverse effects in these neonatal animals. 
Limited data are available on absorption and bioavailability of orally administered rhG-CSF. With a range of 3-4 g body weight for the pups used in this study, the high dose of $300 \mathrm{ng}$ equates to a $75-$ to $100-\mu \mathrm{g} / \mathrm{kg}$ dose, approximately 10 times the dose used for i.v. or s.c. rhG-CSF administration in human neonates $(25,26)$. In a study of very high dose $(300$ or 600 $\mu \mathrm{g} / \mathrm{kg}$ ) rhG-CSF feeding to adult rats, Takada et al. (27) injected rhG-CSF directly into the duodenum and noted a 2 -fold increase in the total blood leukocyte count. Also studying adult rats, Jensen-Pippo et al. (28) reported that the bioavailability of rhG-CSF was undetectable after duodenal administration of $755 \mu \mathrm{g} / \mathrm{kg}$ rhG-CSF. They did not observe any change in blood leukocytes after enteral rhG-CSF administration. It is not clear why differences in the leukocyte count were observed by Takada et al. and not by Jensen-Pippo et al. Both studies used much higher doses of rhG-CSF (4-10 times higher) than in the present study, both studied adult rats, and both used a surgically placed duodenal tube for delivery of the rhG-CSF. The surgical stress could have influenced the total neutrophil count observed in one of these studies.

In a separate study, we measured the bioavailability of enterally administered rhG-CSF ( 3 and $300 \mathrm{ng}$ ) to neonatal wild-type mice and neonatal mice with a targeted deletion in the G-CSF-R gene, rendering it nonfunctional (29). In both groups, the bioavailability of G-CSF was $<1 \%$ and was not affected by the absence of a functional G-CSF-R. Because the bioavailability of enterally administered rhG-CSF is so low in neonatal animals, one would not expect to observe a significant change in neutrophil count.

We observed that enterally administered rhG-CSF to suckling mice resulted in an increase in certain intestinal morphometric measurements. The increased villus area, perimeter, and length that we observed correspond with the type of intestinal growth observed when neonatal animals were fed Epo, IGF, or EGF $(4,7-9,11,13,30,31)$. In addition to the staining of cells located in the crypt, we observed PCNA staining of cells within the core of the lamina propria. To further clarify the nature of these cells, we performed additional staining using hematoxylin and eosin. The cells were primarily reticular cells of the stroma with occasional lymphocytes, macrophages, neutrophils, and eosinophils. No difference in cellular distribution was noted between the groups.

Comparing the measurements of the control subjects (those that were fed heat-inactivated rhG-CSF) after 3 versus $7 \mathrm{~d}$ reveals the expected fall in ANC and the expected growth in intestinal morphometric indices during this period. Klein et al. (32) reported similar increases in growth in the developing rat ileum. We anticipated that increasing the duration of rhG-CSF administration from 3 to $7 \mathrm{~d}$ would result in increased indices of growth. However, we speculated that natural growth and proliferation of the developing intestine during this period could mask any effects from administering a low dose of rhG-CSF. Indeed, this might be the reason that the results do not differ between groups 3 and 4 .

The use of a pharmacologic dose of rhG-CSF resulted in additional detectable intestinal growth (group 6 versus group 5). Comparison of the physiologic (group 4) and pharmacologic doses (group 6) revealed increased villus area, perimeter, length, and PCNA index. Because G-CSF-R are present on the apical surface of enterocytes and crypt cells, perhaps the differences in effect represent different binding affinities of receptors on these cells and/or expression of different isoforms of the G-CSF-R (33).

Although this is the first study to evaluate simultaneously both systemic and local intestinal effects of enteral rhG-CSF in neonatal mice, similar studies have been done using Epo, EGF, and IGF $(4,7-9,11,13,32,34)$. After enteral ${ }^{125}$ I-rhEpo dosing, Miller-Gilbert et al. (8) observed that intact ${ }^{125}$ I-rhEpo was found in gastric and small intestinal walls and lumens. Juul et al. (34) found that among rEpo treated pups, 1) the small bowel was longer, 2) the intestinal villus surface areas was larger in a dose-dependent manner, and 3) BrdU uptake was greater.

Shen and $\mathrm{Xu}$ found that $>95 \%$ of orally administered ${ }^{125} \mathrm{I}$-EGF in newborn and 5-d-old pigs was in the GI tract (13). Houle et al. (35) reported a $40 \%$ increase in jejunal DNA content, greater BrdU incorporation, increased enterocyte proliferation, and a modest effect ( $20-40 \%$ over formula alone) on villus height in piglets that were fed formula that contained $131 \mathrm{nmol} / \mathrm{L}$ IGF-I. When pharmacologic concentrations were used $(\sim 1.3 \mathrm{mM})$, significant increases in mucosal protein content, mucosal mass, and villus height occurred (28).

The similarities in effects on intestinal growth noted between Epo, EGF, and our findings using G-CSF could be due to each cytokine's receptor belonging to the same cytokine superfamily (36-38). In hematopoietic cells, Epo and G-CSF bind to their cognate receptor and initiate intracellular signaling via the janus kinase and signal transducer and activator of transcription protein pathways (36-38). The specific events triggered by Epo and G-CSF on intestinal epithelial cells are not known. However, G-CSF-R and Epo-R are present on intestinal epithelial cells in human fetuses and neonates $(22,33,39)$, and the full-length G-CSF-R (isoform I), which is required for proliferation, differentiation, and enhanced cell viability in myeloid cells (36), is present throughout gestation (33). These findings suggest that it is possible for the G-CSF-R and Epo-R on intestinal epithelial cells to initiate proliferation and differentiation and enhance cell viability as is seen in hematopoietic cells. Further studies are necessary to confirm the specific intracellular signaling pathways used by human intestinal epithelial cells.

In conclusion, this study demonstrates that rhG-CSF administered enterally to suckling mice does not increase the ANC but has trophic effects on the intestine. On this basis, we speculate that the G-CSF normally swallowed by the fetus and neonate has minor if any systemic effects but acts as a trophic factor in the intestinal villi. Future studies on the bioavailability of enterally administered rhG-CSF, the expression of GCSF-R isoforms on various fetal and neonatal intestinal tissues, and the specific function of G-CSF in the developing intestine will aid our understanding of the nonhematopoietic roles of G-CSF during GI development.

\section{REFERENCES}

1. Podolsky DK 1993 Regulation of intestinal epithelial proliferation: a few answers, many questions. Am J Physiol 264(suppl):179-186 
2. Thomson AB, Keelan M 1986 The development of the small intestine. Can J Physiol Pharmacol 64:13-29

3. Baumrucker CR, Hadsell DL, Blum JW 1994 Effects of dietary insulin-like growth factor I on growth and insulin-like growth factor receptors in neonatal calf intestine. J Anim Sci 72:428-433

4. Berseth CL 1987 Enhancement of intestinal growth in neonatal rats by epidermal growth factor in milk. Am J Physiol 253(suppl):662-665

5. Carpenter G 2000 The EGF receptor: a nexus for trafficking and signaling. Bioessays 22:697-707

6. Chew S, Nakamura K, Petropoulos A 1994 Multiple actions of epidermal growth factor and TGF-alpha on rabbit gastric parietal cell function. Am J Physiol 267:G818-G826

7. Houle VM, Schroeder EA, Odle J, Donovan SM 1997 Small intestinal disaccharidase activity and ileal villus height are increased in piglets consuming formula containing recombinant human insulin-like growth factor-I. Pediatr Res 42:78-86

8. Miller-Gilbert AL, Dubuque SH, Dvorak B, Williams CS, Grille JG, Woodward SS, Koldovsky O, Kling PJ 2001 Enteral absorption of erythropoietin in the suckling rat Pediatr Res 50:261-267

9. Pollack PF, Goda T, Colony PC, Edmond J, Thornburg W, Korc M, Koldovsky O 1987 Effects of enterally fed epidermal growth factor on the small and large intestine of the suckling rat. Regul Pept 17:121-132

10. Penttila I, Van Spriel A, Zhang M, Xian C, Steeb C, Cummins A, Zola H, Read L 1998 Transforming growth factor-B levels in maternal milk and expression in postnatal rat duodenum and ileum. Pediatr Res 44:524-531

11. Steeb C, Trahair J, Read L 1995 Administration of insulin-like growth factor-1 (IGF-1) peptides for three days stimulates proliferation of the small intestine epithelium in rats. Gut 37:630-638

12. Odle J, Zijlstra RT, Donovan SM 1996 Intestinal effects of milkborne growth factors in neonates of agricultural importance. J Anim Sci 74:2509-2522

13. Shen WH, Xu RJ 1998 Stability and distribution of orally administered epidermal growth factor in neonatal pigs. Life Sci 63:809-820

14. Fellah AM, Philipps AF, Gillespie TJ, Galo JR, Dvorak B 2001 Degradation of insulin-like growth factors in small intestine of suckling rats. Regul Pept 98:19-25

15. La Gamma EF, De Castro MH 2002 What is the rationale for the use of granulocyte and granulocyte macrophage colony-stimulating factors in the neonatal intensive care units? Acta Paediatr Suppl 91:109-116

16. Calhoun DA, Christensen RD 2000 Human developmental biology of granulocyte colony-stimulating factor. Clin Perinatol 27:559-576

17. Calhoun DA, Chegini N, Polliotti BM, Gersting JA, Miller RK, Christensen RD 2001 Granulocyte colony-stimulating factor in preterm and term pregnancy, parturition, and intra-amniotic infection. Obstet Gynecol 97:229-234

18. Calhoun DA, Lunoe M, Du Y, Christensen RD 2000 Granulocyte colony-stimulating factor (G-CSF) is present in human milk and its receptor (G-CSF-R) is present in human fetal intestine. Pediatrics 2000:105(1). Available at: www.pediatrics.org/cgi/ content/full/105/1/e7

19. Calhoun DA, Lunoe M, Du Y, Staba S, Christensen RD 1999 Concentrations of granulocyte colony-stimulating factor in human milk after in vitro simulations of digestion. Pediatr Res 46:767-771

20. Calhoun DA, Richards B, Gersting JA, Sullivan SE, Christensen RD 2002 G-CSF and erythropoietin stability in amniotic fluid during simulated in vitro digestion conditions. J Pharm Technol 18:310-315

21. Li Y, Calhoun DA, Polliotti BM, Sola MC, Al-Mulla Z, Christensen RD 1996 Production of granulocyte colony-stimulating factor by the human placenta at various stages of development. Placenta 17:611-617

22. Calhoun DA, Donnelly Jr WH, Du Y, Dame JB, Li Y, Christensen RD 1999 Distribution of granulocyte colony-stimulating factor (G-CSF) and G-CSF-receptor mRNA and protein in the human fetus. Pediatr Res 46:333-338
23. Cairo MS, Plunkett JM, Mauss D, Van de ven C 1990 Seven-day administration of recombinant human granulocyte colony-stimulating factor to newborn rats: modulation of neonatal neutrophilia, myelopoiesis and group B Streptococcus sepsis. Blood $76: 1788-1794$

24. Argenzio RA, Liacos JA, Levy ML, Meuten DJ, Lecce JG, Powell DW 1990 Villous atrophy, crypt hyperplasia, cellular infiltration, and impaired glucose-Na absorption in enteric cryptosporidiosis of pigs. Gastroenterology 98(suppl):1129-1140

25. Barak Y, Leibovitz E, Mogilner B, Juster-Reicher A, Amitay M, Ballin A, Koren A, Goebel M 1997 The in vivo effect of recombinant human granulocyte-colony stimulating factor in neutropenic neonates with sepsis. Eur J Pediatr 156:643-646

26. Bedford Russell AR, Emmerson AJ, Wilkinson N, Chant T, Sweet DG, Halliday HL, Holland B, Davies EG 2001 A trial of recombinant human granulocyte colony stimulating factor for the treatment of very low birthweight infants with presumed sepsis and neutropenia. Arch Dis Child Fetal Neonatal Ed 84:172-176

27. Takada K, Tohyama Y, Oohashi M, Yoshikawa H, Muranishi S, Shimosaka A, Kaneko T 1989 Is recombinant human granulocyte colony-stimulating factor (G-CSF) orally available in rats? Chem Pharm Bull (Tokyo) 37:838-839

28. Jensen-Pippo KE, Whitcomb KL, DePrince RB, Ralph L, Habberfield AD 1996 Enteral bioavailability of human granulocyte colony stimulating factor conjugated with poly(ethylene glycol). Pharmacol Res 13:102-107

29. Gersting JA, Kotto-Kome CA, Du Y, Christensen RD, Calhoun DA 2003 Bioavailability of granulocyte colony-stimulating factor administered enterally to suckling mice. Pharmacol Res 48:643-647

30. Burrin DG, Wester TJ, Davis TA, Amick S, Heath JP 1996 Orally administered IGF-I increases intestinal mucosal growth in formula-fed neonatal pigs. Am J Physio 270(suppl): 1085-1091

31. Buhler C, Hammon H, Rossi GL, Blum JW 1998 Small intestinal morphology in eight-day-old calves fed colostrum for different durations or only milk replacer and treated with long-R3-insulin-like growth factor I and growth hormone. J Anim Sci 76:758-765

32. Klein RM, McKenzie JC 1980 Pattern of crypt cell proliferation in the pre- and postclosure ileum of the neonatal rat: effects of sympathectomy. Cell Tissue Res 206:387-394

33. Gersting JA, Du Y, Christensen RD, Calhoun DA 2003 Messenger RNA expression of granulocyte colony-stimulating factor receptor isoforms in the fetus. Biol Neonate 83:191-196

34. Juul SE, Ledbetter DJ, Joyce AE, Dame C, Christensen RD, Zhao Y, DeMarco V 2001 Erythropoietin acts as a trophic factor in neonatal rat intestine. Gut 49:182-189

35. Houle VM, Park YK, Laswell SC, Freund GG, Dudley MA, Donovan SM 2000 Investigation of three doses of oral insulin-like growth factor on jejunal lactase phlorizin hydrolase activity and gene expression and enterocyte proliferation and migration in piglets. Pediatr Res 48:497-450

36. Hermans MHA, Van de Geijn GJ, Antonissen C, Gits J, van Leeuwen D, Ward AC, Touw IP 2003 Signaling mechanisms coupled to tyrosines in the granulocyte colonystimulating factor receptor orchestrate G-CSF induced expansion of myeloid progenitor cells. Blood 101:2584-2590

37. Tarnawski AS, Jones MK 1998 The role of epidermal growth factor (EGF) and its receptor in mucosal protection, adaptation to injury, and ulcer healing: involvement of the EGF-R signal transduction pathways. J Clin Gastroenterol 27:S12-S20

38. Barber DL, Beattie BK, Mason JM, Nguyen MH, Yoakim M, Neel BG, D'Andrea AD, Frank DA 2001 A common epitope is shared by activated signal transducer and activator of transcription-5 (STAT5) and the phosphorylated erythropoietin receptor: implications for the docking model of STAT activation. Blood 97:2230-2237

39. Juul SE, Yachnis AT, Christensen RD 1998 Tissue distribution of erythropoietin and erythropoietin receptor in the developing human fetus. Early Hum Dev 52:235-249 